NBER WORKING PAPER SERIES

\title{
PROFITABLE INVESTMENTS OR DISSIPATED CASH? EVIDENCE ON THE INVESTMENT-CASH FLOW RELATIONSHIP FROM OIL AND GAS LEASE BIDDING
}

\author{
Marianne Bertrand \\ Sendhil Mullainathan \\ Working Paper 11126 \\ http://www.nber.org/papers/w11126
NATIONAL BUREAU OF ECONOMIC RESEARCH
1050 Massachusetts Avenue
Cambridge, MA 02138
February 2005

We are grateful to Jeremy Stein, as well as to seminar participants at the University of Chicago Graduate School of Business, Harvard Business School, Harvard University, University of Michigan, University of British Columbia, Wharton, Yale Law School, Stanford University, University of Illinois, Georgia Tech and the NBER Organizational Economics conference, for many helpful comments. Nahid Rahman provided excellent research assistance. The views expressed herein are those of the author(s) and do not necessarily reflect the views of the National Bureau of Economic Research.

(C) 2005 by Marianne Bertrand and Sendhil Mullainathan. All rights reserved. Short sections of text, not to exceed two paragraphs, may be quoted without explicit permission provided that full credit, including () notice, is given to the source. 
Profitable Investments or Dissipated Cash? Evidence on the Investment-Cash Flow Relationship From Oil and Gas Lease Bidding

Marianne Bertrand and Sendhil Mullainathan

NBER Working Paper No. 11126

February 2005

JEL No. G3

\begin{abstract}
$\underline{\text { ABSTRACT }}$
The strong positive relationship between corporate cash flow and investment has been interpreted through the lens of both agency- and non-agency-based models. In this paper, we distinguish between these two interpretations using project-level data in the oil and gas industry. The specific projects we consider are auctioned-off leases that give mineral exploration rights to tracts of federal land. We find the standard positive relationship between investment and cash flow in this data, in that positive shocks to residual cash flow (netting out firm and time effects) are associated with higher spending on these leases. Interestingly, the increased investment comes from an increase in the price paid per tract with little to no change in the total number of tracts or total acreage of land bought. The positive association between price and cash flow holds even after controlling for a set of tract and firm characteristics that might be ex-ante related to expected return on a given tract. This data is most useful, however, because we can directly observe the eventual productivity of each of these projects. We find that the increase in price induced by higher cash flow is associated with lower average productivity. In fact, the total number of productive tracts does not increase with cash flow. In other words, while higher cash flow is associated with higher spending on these projects, higher cash flow does not lead to higher revenues from these projects. Combining this finding with the lack of a quantity response, we conclude that our results are best described by an agency model where managers use cash flow to simplify their job (or live a "quiet life") rather than "empirebuild."
\end{abstract}

Marianne Bertrand

Graduate School of Business

University of Chicago

5807 South Woodlawn Avenue

Chicago, IL 60637

and NBER

marianne.bertrand@chicagogsb.edu

\author{
Sendhil Mullainathan \\ Department of Economics \\ Littauer 208 \\ Harvard University \\ Cambridge, MA 02138 \\ and NBER \\ mullain@fas.harvard.edu
}




\section{Introduction}

In a variety of data sets, firm cash flow has been found to predict capital expenditures often much better than standard measures of investment opportunities or cost of capital (Caballero 1999, Stein 2003). What can explain this finding? Three main interpretations have been proposed. The first, a mis-measurement (or omitted variable) interpretation, argues that cash flow proxies for investment opportunities. Under this interpretation, greater cash flow is simply correlated with the availability of profitable investment projects (Poterba 1988). The second, a financing constraint interpretation, argues that added cash flow gives firms the resources to undertake profitable projects that they otherwise could not (Fazarri, Hubbard and Petersen, 1988). The third, an agency-based interpretation, argues that managers may dissipate "free" cash flow on wasteful investments for private gain (Jensen 1986).

Much of the theoretical and empirical debate surrounding this question has focused on the mismeasurement interpretation, reaching rather mixed conclusions so far. Several papers have shown that Tobin's Q may indeed be a poor proxy for the true fundamental determinants of a firm's investment opportunities and that cash flow may contain valuable information about such opportunities (see for example Erickson and Whited 2000 or Alti 2003). Yet, other papers have shown that capital expenditures are also significantly affected by increases in cash flow that are plausibly exogenous to changes in investment opportunities (Lamont 1997, Shin and Stultz 1998, Rauh 2004), thereby seriously undermining a pure mis-measurement interpretation.

Assuming there is indeed some causal link between cash flow and investment, it is still an open question as to whether the additional capital expenditures generated by greater cash flow are profitable (financing constraint interpretation) or wasteful (agency interpretation). ${ }^{1}$ Data constraints have so far prevented researchers from directly tackling this question. Indeed, most of the prior research relies on balance-sheet data, which does not include information on the specific projects undertaken when firms experience a positive shock to their cash flow, much less on the outcome of these projects.

In this paper, we re-examine the investment-cash flow relationship in a data set where both individual investment projects and the outcome of these projects can be evaluated. The specific investment projects we focus on are mineral exploration leases. The federal government routinely auctions off exploration rights to offshore tracts. Firms bid on these tracts in order to have exclusive rights to explore them and, in the case oil, gas or other minerals are found, extract resources from them. The data set details for each tract

\footnotetext{
${ }^{1}$ Fazzari, Hubbard and Petersen (1988) tested the financing constraint interpretation by comparing investment-cash flow sensitivities across groups of firms that they define as ex ante more or less financially constrained. Kaplan and Zingales (1997) started a long debate in the literature on the theoretical and empirical validity of this exercise. Rauh (2004) finds more robust support for a financing constraint interpretation when relying on exogenous shock to cash flow.
} 
the amount bid by all bidding firms (both winners and losers), the identity of these bidding firms, the exact timing of the bid (month and year), and numerous tract-level characteristics that may be predictive of the tract's eventual productivity. Most importantly, we also observe for each tract whether or not it was eventually found productive and, for a subset of the productive tracts, the exact quantity of minerals extracted. The structure of the data therefore allows us to identify the marginal project undertaken when cash flow increases, as well as to track eventual return on this marginal project.

We first establish that the standard investment-cash flow relationship holds in this data set. In a panel regression that includes both firm and year fixed effects, we show that higher cash flow is associated with higher total spending on oil and gas leases. ${ }^{2}$ Interestingly, this positive relationship between total expenditures and cash flow is not driven by a quantity response. Positive shocks to cash flow are not associated with firms buying more tracts or more acreage of land. Instead, the relationship between total expenditures and cash flow is driven by a price response. Firms bid more for each acre of land as their cash flow increases. The bid price-cash flow relationship is robust to controlling for a set of physical tract characteristics that are observable by all bidding firms prior to the auction. More tellingly, the bid pricecash flow relationship estimated on the set of winning bids is also robust to controlling for the second highest bid in the auction.

We then study the productivity of the tracts that are bought when residual cash flow is greater. Our basic measure of productivity is whether or not a tract is declared productive before the lease expiration date, i.e. whether or not minerals are found in the tract. While previous papers have documented that a higher bid price positively predicts whether a given tract will eventually be found productive (see Hendricks and Porter 1996), we find that cash flow-induced increases in bid price are, if anything, negatively related to eventual productivity. More importantly, in a simple panel regression that controls for firm and year fixed effects, we find that the overall number of productive tracts does not increase with a firm's cash flow in the year these tracts were bought. In other words, while we establish that higher cash flow is associated with higher spending on these projects, higher cash flow is not associated with a larger number of productive projects. We also show that this result is not an artifact of focusing on the probability of success as a return measure. Focusing on a subset of productive tracts for which we have detailed information on the amount of resources extracted, we find no evidence that productive tracts bought when cash flow is high systematically generate more resources. These findings contradict a profit maximization-based explanation

\footnotetext{
${ }^{2}$ The inclusion of year fixed effects means that we are not simply picking up on an industry wide phenomenon, such as all firms bidding more when the price of oil increases. The inclusion of firm fixed effects means that we are not simply picking up on other time-invariant firm characteristics that are systematically correlated with average differences in cash flow across firms.
} 
for the investment-cash flow relationship in this data set. Instead, they are more consistent with a free cash flow interpretation. ${ }^{3}$

Many industry observers perceive that the oil industry experienced large improvements in corporate governance in the 1980s. Increases in both takeover activity and in the threat of takeovers are thought to have reduced some of the managerial misbehavior posited by the free cash flow view. We find that bid prices are sensitive to cash flow throughout the sample period (mid 1960s to late 1990s). But in the later years of our sample (post-1985), the profitability of tracts bought when cash flow is high does improve. This last fact at least matches the prior belief of an improvement in corporate governance. ${ }^{4}$

While our results support a free cash flow model of bidders' behavior (especially prior to the mid 1980s), there is one important caveat. Free cash flow models often also assume that managers seek to build empires (Jensen 1986). Yet, in our data, we find no evidence that bidders attempt to increase the scale of their operations when cash flow increases: they are not bidding on more tracts or more total acreages of land. Instead, they simply appear to be making worse decisions and dissipating cash through higher bid prices. In this sense, our results appear to be most consistent with "quiet life" models of free cash flow, in which managers use cash on hand to make their job easier (Hicks 1935, Bertrand and Mullainathan 2003). One simple model that would fit the facts uncovered in our empirical analysis would involve a trickling down of extra cash flow through the organizational hierarchy. When cash flow is high, top management may increase investment budgets throughout the firm, either explicitly or by being more lenient towards budgetary requests. This increased budget gives lower-level management the ability to spend cash to make their jobs easier. Overpaying for leases can occur either because these lower-level managers want to avoid the private costs of generating information about the tracts or the private costs of finding new tracts if their earlier bids fail. ${ }^{5}$

The rest of this paper is organized as follows. Section 2 presents a brief overview of the industry. We describe the data in Section 3. Section 4 proposes a simple theoretical framework aimed at guiding the interpretation of the empirical analysis. Our main findings are presented in Section 5. We address possible alternative interpretations in Section 6.1. Section 6.2 discusses how our findings might or might not generalize to other industrial contexts. We conclude in Section 7.

\footnotetext{
${ }^{3}$ As we will discuss in more detail below, diminishing returns cannot explain why the overall number of productive leases fail to rise with cash flow.

${ }^{4}$ Though of course this change could be driven by many other aggregate time shocks, such as changes in exploration technology.

${ }^{5}$ As we discuss in Section 6.2, our findings may therefore more directly generalize to other investment projects decided upon lower down in the organizational hierarchy.
} 


\section{Description of Industry Context}

Since 1954, the U.S. Department of Interior has been auctioning off leases that give mineral exploration rights to tracts of federal land. These tracts are located in Alaska, offshore in the Pacific and offshore in the Gulf of Mexico. For data availability reasons, we will focus in this paper on sales in the Gulf of Mexico. Each sale is a simultaneous auction of typically more than a hundred tracts and there are several sales taking place each year. The auction format is first-price, sealed bid. The highest bidder for each tract is usually awarded the lease in exchange for the amount bid, unless the government deemed the amount bid as insufficient. These leases represent fairly large investment projects. The average lease in our sample is sold for $\$ 12.5$ million dollars (in 2000 dollars). Firms who bid on these tracts vary dramatically in size, from subdivisions of large publicly traded firms to small partnerships bidding on a couple of tracts every few years.

In order to inform their bidding decisions, firm often conduct seismic surveys or purchase such surveys from geophysical companies. Each firm uses this survey data to identify geologically attractive tracts and then conducts an in-depth evaluation of these tracts (Hendricks, Pinske and Porter 2003). In addition, because tracts located within the same area are likely to share common geological features, firms can also rely on the publicly observed successes or failures of previously auctioned nearby tracts. Finally, firms may also have some private information if they own some nearby successful tracts. ${ }^{6}$

When a firm wins a tract, it can explore the tract for the length of the lease (typically five years). A rent, typically of $\$ 3$ per acre, is paid by the firm each year of the lease until discovery of minerals or until the lease expires. Exploration typically involves drilling boreholes and testing for the presence of gas, oil, or other minerals. If the lease expires without discovery of any major oil and/or gas reserves, the government regains ownership of the tract. If minerals are discovered before the expiration date, the lease is automatically renewed for as long as the tract is producing minerals. So exploration leases effectively give monopoly rights to extraction as well. Once production begins, the government receives a fixed fraction of production revenues (typically 16.7 percent) as a royalty payment. Royalty rate, rental rates and lease length are known prior to bidding.

\footnotetext{
${ }^{6}$ As described below, firms typically have a five year window from purchase to report of any mineral findings or the lease reverts to the government. Since such reports are public, this limits the time horizon in which firms can keep successes private.
} 


\section{Data}

The Minerals Management Service (MMS) keeps detailed information on all leases auctioned off in the Gulf of Mexico since 1954. For each lease, the data contain, among other things: complete bidding information (all recorded bids with name of the bidding companies), tract characteristics (size, maximum and minimum depth, location), contract characteristics (rental rate, royalty rate, length of lease), and whether or not the lease ended up being found productive at the end of the exploration period.

We merge this lease-level information to firm-year balance sheet information from COMPUSTAT. Because the MMS and COMPUSTAT do not share the same company identifiers, we merge the two data sets by hand based on company names. One operational difficulty is the treatment of subsidiaries. Indeed, large publicly traded oil companies often appear in the MMS data through fully or partly owned subsidiaries that specialize in exploration activities. We use company directories (such as One Source) to match a given subsidiary to its parent company. About 40 percent of all bids in the MMS data belong to privately held stand-alone firms. Such firms are not covered in COMPUSTAT and therefore not included in our final sample. Also, while the MMS data is available from 1954 on, COMPUSTAT data only starts in 1963. Our final dataset covers about 120 firms over the 1963-1999 period.

We use COMPUSTAT to measure cash flow and investment opportunities for the firms in our sample. We define cash flow as the sum of earnings before extraordinary items (COMPUSTAT item 18) and depreciation (item 14); we deflate this measure by capital, which is measured as net property, plant and equipment (item 8) at the beginning of the fiscal year. We measure average Tobin's $\mathrm{Q}$ as the market value of assets divided by the book value of assets (item 6). The market value of assets is defined as the book value of assets plus the market value of common equity less the sum of the book value of common equity (item 60) and balance sheet deferred taxes (item 74). We calculate average Tobin's $\mathrm{Q}$ at the beginning of the fiscal year. From COMPUSTAT, we also extract total capital expenditures for the firms in our sample (item 128), which we deflate by net property, plant and equipment at the beginning of the fiscal year.

Summary statistics are reported in Table 1. The unit of observation is a bid (placed by a given company on a given lease). We present summary statistics for all bids (column 2) as well as for the sub-sample of winning bids (column 3). The average size of a tract is about 5000 acres and the average bid price per acre is $\$ 2,500$ (in 2000 dollars). About 30 percent of the bids were on tracts that were later found productive. Because we exclude smaller private bidders for lack of balance sheet data, the firms included in our final sample are very large. Total assets for the median firm is $\$ 2$ billion (in 2000 dollars). Firms in our sample 
bid on average for 9 different tracts every year and win on average $7 .^{7}$ We calculated that expenditures on these tracts represent on average about 5 percent of total capital expenditures for the firms included in our sample.

\subsection{Overall Investment}

Since we are focusing on a specific industry and specific type of investment projects, two preliminary questions come to mind. First, do the firms in our sample display the usual positive correlation between cash flow and balance sheet capital expenditures? Second, how does spending on the leases that will be the focus of our detailed project-level data relate to overall capital expenditures? We address the first question in Panel A of Table 2 and the second in Panel B of that table.

In column 1 of Panel A, we regress the logarithm of capital expenditures on the logarithm of cash flow for the panel of all firms ever present in our sample, whether or not this is a bidding year for these firms. ${ }^{8}$ We further control for firm and year fixed effects. Also, in this table, as well as in all following tables, standard errors are estimated allowing for correlation of the error term at the firm level.

We find a positive and statistically significant relationship between total investment and cash flow for the firms in our sample. A 1 percent increase in cash flow leads to .4 percent increase in capital expenditures. In column 2, we further control for Tobin's Q. We find a positive relationship between capital expenditures and Tobin's Q. The inclusion of this additional control for investment opportunities however barely alters the investment-cash flow sensitivity estimated in column 1 . In the remaining columns of Panel A, we replicate the specification of column 2 but only include those firm-year observations that correspond to bidding years (column 3) or winning years (column 4) for a given firm. We obtain results qualitatively similar to those in column 2 for these two unbalanced panels.

In Panel B of Table 2, we examine how bidding and spending on the leases covered in our project-level data relates to balance sheet capital expenditures. In column 1, the dependent variable is a dummy variable that equals 1 if a firm places at least one bid in that year. We regress this dummy variable on the logarithm of total capital expenditures, further controlling for firm and year fixed effects. We find a positive and statistically significant relationship. The same holds in column 2 where the dependent variable is now a dummy variable that equals 1 if a firm wins at least one auction in that year. In the rest of Panel B, we relate total amount bid (conditional on bidding on at least one lease in that year) and total amount spent

\footnotetext{
${ }^{7}$ Such high success rates raise questions of collusion, an issue we return to in Section 6.

${ }^{8}$ Similar results follow if we use a level-level rather than a logarithm-logarithm specification. We however focus on a logarithm-logarithm specification throughout the paper since it fits the data best. This results in us dropping the small fraction of observations (about 4 percent) where cash flow is negative.
} 
(conditional on winning at least one lease in that year) to total capital expenditures. Both total amount bid and total amount spent are deflated by net property, plant and equipment at the beginning of the fiscal year. A 1 percent increase in capital expenditures is associated with a .52 percent increase in the amount bid (column 3) and a .45 percent increase in the amount spent (column 4) on oil and gas leases.

Whether the results we document below generalize to other industries or other types of investment projects is of course an empirical question. But the findings in Table 2 suggest that we are at the very least not focusing on a particularly atypical case. Panel A shows that firms in this industry display the positive correlation between cash flow and total capital expenditures that has been empirically observed in other sectors of the economy. Panel B shows that the particular type of capital expenditures we are focusing on co-moves with the other types of capital expenditures these firms undertake.

\section{$4 \quad$ Framework}

In order to guide the empirical work below, we present a simple model of investment. The goal of this framework is not to elucidate optimal bidding behavior but instead to clarify what the different theories of the investment-cash flow sensitivity would imply for the project-level data we study.

Whenever a firm wins a lease, the profits generated by this single lease is defined to be:

$$
p(R-C)-I-E,
$$

where $p$ is the probability of finding minerals, $R$ is the revenue generated by the lease (conditional on finding minerals), $C$ are production/extraction costs (conditional on finding minerals), $I$ is the price paid for the lease and $E$ are exploration costs.

In principle, each of these variables may potentially depend on cash flow, and we make two simplifying assumptions in the empirical work below. First, we assume that production and extraction costs for a given lease are not related to cash flow. This assumption seems validated, at least anecdotally, by the fact that extraction technologies are fairly uniform within sets of tracts sharing the same basic geological features (depth, location) and within time periods, variables that we control for in the empirical analysis. ${ }^{9}$ By the same token, we assume that exploration costs do not vary with cash flow.

\footnotetext{
${ }^{9}$ We directly investigated whether cash flow relates to some physical characteristics of the tracts bid on that might be associated with lower costs (such as tract depth). We found no evidence for this. Also, one may argue that, even holding tract characteristics and year constant, costs may vary firm by firm based on the location of the tracts they have won in the past. For example, a firm may have relatively lower costs on a tract if that firm is already exploring or producing in several neighboring tracts. However, as we show in Table 7, we find no systematic evidence that cash rich firms are more likely to bid on tracts located in areas where they already have a strong presence.
} 
Second, we also assume for now that that the revenues generated by a given lease, conditional on the lease being productive, are not related to cash flow. Of course this needs not be the case. For example, bidders with high cash flow may bid on riskier projects. In practice, we will explicitly test this simplifying assumption in the last part of the paper (for a subset of productive leases) and find that this assumption holds in the data. ${ }^{10}$

Bid price $(I)$ and probability of success $(p)$ are assumed to vary with cash flow. We also assume that the number of leases bought, which we denote $N$, vary with cash flow. ${ }^{11}$ Because of diminishing returns, we also assume that the probability of finding minerals on any one lease may change with the number of leases bought. Given the assumptions above, we can now express profit per lease and total profits as:

$$
\begin{aligned}
\pi(C F) & =p(C F, N)(R-C)-I(C F)-E \\
\Pi(C F) & =N(C F)[p(C F)(R-C)-I(C F)-E]
\end{aligned}
$$

Differentiating with respect to cash flow shows how average and total lease profits vary with cash flow:

$$
\begin{aligned}
\pi_{C F} & =p_{C F}(R-C)+p_{N} N_{C F}(R-C)-I_{C F} \\
\Pi_{C F} & =\frac{\partial(p * N)}{\partial C F}(R-C)-\frac{\partial(I * N)}{\partial C F}
\end{aligned}
$$

with $p_{N} \leq 0$, because of diminishing returns.

What do the different theories of the investment-cash flow sensitivity say about how these different variables respond to cash flow? Table 3 provides a summary of these predictions. Obviously, all three theories, by definition, predict that $I * N$ will increase with cash flow.

Consider now how total profits vary with cash flow: $\Pi_{C F}$. Liquidity constraint and mis-measurement theories assume profit maximization and hence must imply that $\Pi_{C F} \geq 0$ : total profits must rise with cash flow. Since expenditures are increasing with cash flow, revenues must rise to offset this increase. This in turn implies within our framework that the total number of successes $p * N$ must rise with cash flow. Under the free cash flow theory, however, profit maximization is not assumed by definition. Consequently, it is only under this theory that the total number of successes, $p * N$, may not rise with cash flow. In fact, $p * N$ may even fall under that theory if cash-rich managers end up buying worse tracts on average.

\footnotetext{
${ }^{10}$ This assumption also fits well with earlier work showing that, while bid price is a strong predictor of whether a given tract will be productive, it is not very predictive of how much resources will be found, conditional on positive output. In other words, while bidders seem able to somewhat predict whether a given lease will be productive or not, they find it much harder to predict its actual output.

${ }^{11}$ In this simplified framework, we assume tracts are homogenous and firms increase quantity by increasing number of leases. In practice, of course, other dimensions such as tract size may vary with cash flow. We will investigate this in detail in the empirical section.
} 
Note that these predictions are only true for total profits and total number of successes. Because of diminishing returns, a drop in average profit and average success rate as cash flow increases could be reconciled with all three theories. To see this, note that in equation (1), $\pi_{C F}$ could be negative if $N_{C F}$ is positive, as $p_{N}$ is less or equal to zero due to diminishing returns.

In practice, we will empirically study each of the following factors. First, we will study the relationship between total spending on leases $(N * I)$ and cash flow $(C F)$. This first step is equivalent to the investmentcash flow regressions previously estimated with more standard capital expenditures data. Obviously, as mentioned above, all three views of the investment-cash flow sensitivity predict that $I * N$ increases with cash flow.

We will then decompose this total spending effect into a quantity effect $(N)$ and a price effect $(I) .{ }^{12} \mathrm{~A}$ study of the quantity response is relevant in at least two regards. First, as we discussed above, the profitmaximization and free cash flow models have systematically different implications for average profit and average success rate only in the absence of a quantity response. Indeed, without scale effects $\left(N_{C F} \approx 0\right)$, profit-maximization implies not only that total profits but also that average profit must rise with cash flow.

A study of the quantity response is also interesting in its own right. If the presumption is that higher cash flow proxies for higher investment opportunities or eases liquidity constraints, then one would intuitively expect a positive quantity response. In contrast, under the free cash flow theory, the effect of cash flow on number of leases bought depends purely on assumptions about managerial preferences. While empire building theories might imply a positive quantity response, other theories (which we classify together as "quiet life" theories) may imply no such response. ${ }^{13}$

Next, we will study how cash flow affects the likelihood of success for the average tract. As noted earlier, average probability of success and average profit can theoretically not increase with cash flow in all three models: because of diminishing returns in the profit-maximization models, and also because of mismanagement and/or bad project choice in the free cash flow model. However, to preview on some our results below, these average probability of success regressions will be theoretically informative because we do not find any quantity response.

Finally, to even more carefully differentiate between the different theories, we will directly study how total number of successes, $N * p$, varies with cash flow. As noted above, $N * p$ must increase with cash flow under the mis-measurement and liquidity constraints models. Otherwise, total profits would also

\footnotetext{
${ }^{12}$ In practice, we will consider two alternative quantity measures: total number of leases and total acreage of land.

${ }^{13}$ Obviously, if one assumes that tracts vary in observable quality, then it is unclear what "quantity" means in this model. Scale of operations could increase by simply buying fewer higher quality tracts. In fact, in the analysis below, we find neither evidence of a response on number of tracts bought nor evidence that higher cash flow leads firms to bid on tracts that have systematically better observable characteristics.
} 
be decreasing with cash flow (as expenditures rise with cash flow), contradicting the profit maximization assumption. Only under the agency-based free cash flow model may $N * p$ not be increasing with cash flow.

\section{Results}

\subsection{Total Bids and Cash Flow}

In Table 4, we study the relationship between total lease expenditures and cash flow. The first two columns focus on total amount bid in a given year by a given firm (conditional on bidding on at least one lease); the last two columns focus on total amount won in given year by a given firm (conditional on winning at least one lease). Total amount bid and total amount won are deflated by net property, plant and equipment at the beginning of the fiscal year. ${ }^{14}$ Both lease expenditures and cash flow are expressed in logarithms.

Each regression in Table 4 controls for Tobin's Q, as well as firm and year fixed effects. The year fixed effects allow us to net out any aggregate shocks that might be correlated with firm cash flow and lease expenditures, such as changes in the price of oil. Controlling for such year fixed effects is crucial since oil price changes will likely affect both firms' cash flow and the perceived profitability of leases. ${ }^{15}$ The firm fixed effects net out any fixed differences between firms in cash flow and total lease expenditures. For example, some firms may systematically have access to superior information, which could translate into higher cash flow and higher investment level. The inclusion of firm fixed effects ensures that our estimates are not driven by any such fixed differences across firms. Finally, to account for any dependencies across observations caused by serial correlation, standard errors are estimated allowing for correlation of the error term at the firm-level. ${ }^{16}$

In columns 1 and 3, we find a positive and statistically significant relationship between amount bid or spent on oil and gas leases and cash flow. The relationship is very similar in magnitude to that observed for overall capital expenditures in Table 2. A 1 percent increase in cash flow increases amount bid and amount won by about .4 percent.

These regressions assume that a one percent change in cash flow has a uniform effect throughout the cash flow distribution. However, it is possible that a one percent change at the bottom of the cash flow distribution may differentially affect expenditures than a one percent change at the top of that distribution. We investigate such a possibility in columns 2 and 4 where we rely on a more flexible functional form.

\footnotetext{
${ }^{14}$ In case of joint bidding, total amount bid and total amount won are computed based on the fraction of ownership of the firm in the joint bid.

${ }^{15}$ When we move to the lease-level data below, we will also control for the monthly price of oil (in addition to the year fixed effects) as we know the specific month a certain lease was auctioned off.

${ }^{16}$ See Bertrand, Duflo and Mullainathan 2004 for a simple discussion.
} 
Specifically, we "spline" the cash flow variable and allow for different investment-cash flow sensitivities at low cash flow levels (below the 33rd percentile of the cash flow distribution), medium cash flow levels (between 33rd and 66th percentile of the cash flow distribution) and high cash flow levels (above 66th percentile of the cash flow distribution). ${ }^{17}$

Interestingly, the greatest sensitivity of lease expenditures to cash flow is in the middle cash flow range. In fact, there is no sensitivity in the low cash flow range. Investment is positively related to cash flow in the high cash flow range but the relationship is not precisely estimated.

In summary, the findings in Table 4 confirm the positive relationship between lease expenditures and cash flow $\left((N * I)_{C F} \geq 0\right)$. We now proceed with exploiting the project-level nature of our data to better understand what drives this relationship.

\subsection{Decomposition into Price and Quantity Effects}

What drives the observed positive relationship between cash flow and total lease expenditures? Do cash-rich firms bid on and win more leases or do they spend more per lease?

In Table 5, we propose to decompose the aggregate effects of Table 4 into such quantity and price margins. In Panel A, we use as dependent variables the average price per lease bid on (columns 1 and 2) and the average price per lease won (columns 3 and 4). In Panel B, we use as dependent variables the number of leases bid on (columns 1 and 2) and number of leases won (columns 3 and 4). In columns 1 and 3 of both panels, we estimate a linear regression model between cash flow and these price and quantity measures; in columns 2 and 4, we spline the cash flow variable to allow for non-linearity, as described above. The control variables included in all regressions, in addition to cash flow, are Tobin's Q, firm fixed effects and year fixed effects.

Interestingly, we find no statistically significant relationship between cash flow and number of leases bid on or number of leases won (Panel B). The estimated coefficients on cash flow in columns 1 and 3 , while positive, are economically small and statistically insignificant. Only in the low cash flow range does it appear to be a positive, albeit weak, relationship between cash flow and number of tracts bid on or won (columns 2 and 4 of Panel B).

The sensitivity of investment to cash flow observed in Table 4 is solely driven by an increase in the price per lease as cash flow goes up (Panel A). When we allow for non-linearity in this price-cash flow relationship (columns 2 and 4), we find that this price effect is especially strong in the medium and high cash flow ranges. In fact, in the low cash flow range, increases in cash flow are not associated with higher

\footnotetext{
${ }^{17}$ We chose this specification for simplicity. Allowing for more non-linearities in the functional form produces similar results.
} 
bid price per lease.

In regressions not reported here, we performed an alternative decomposition into quantity and price effects. Rather than using number of leases as the quantity measure, we used total acreage of land (either bid on or won). We used average price per acre as the price measure under this alternative decomposition. We found comparable results. In other words, there is no significant relationship between acreages of land bid on or won and cash flow. Instead, the positive relationship between investment and cash flow appears solely driven by an increase in bid price per acre as cash flow goes up. ${ }^{18}$

In summary, the results in Tables 4 and 5 indicate that firms bid and spend more on oil and gas leases when their cash flow increases. In fact, the investment-cash flow sensitivity we observe for these specific projects is quantitatively very similar to the overall investment-cash flow sensitivity (as measured from balance sheet data) for this subset of firms. Interestingly, though, we find no evidence that this investment-cash flow sensitivity reflects an increase in the number of projects undertaken when cash flow rises, except maybe in the lowest cash flow range. This apparent lack of a quantity response appears at odds with a simple financing constraint interpretation of the investment-cash flow sensitivity. The lack of a quantity response also appears at odds with a simple empire-building interpretation. ${ }^{19}$

\subsection{Bid Price per Acre and Cash Flow}

In Table 6, we re-examine the relationship between bid price per acre and cash flow. However, instead of studying average price per acre across all recorded bids for a given firm in a given year, we now study this relationship at the bid-level. This allows us to control for lease-specific characteristics that could not as easily be included in the aggregate regressions described above. Controlling for such lease-specific characteristics is important in order to start separating two main alternative interpretations of the pricecash flow sensitivity observed above. Indeed, this sensitivity may reflect the fact that cash-rich firms tend to bid on higher quality tracts. Alternatively, cash-rich firms may simply be paying more for tracts of similar quality. Under the first interpretation, one would expect the price-cash flow sensitivity to be weakened as one controls for lease-specific characteristics that are correlated with expected productivity.

\footnotetext{
${ }^{18}$ This lack of a quantity response could in principle be driven by the specific nature of this investment project: bidding on a fixed set of leases. As we discuss in Section 6, however, this is unlikely to be the case. While there are a fixed number of tracts auctioned off in any given sale, many tracts go unbought. Expanding on the quantity margin should therefore be quite feasible.

${ }^{19}$ Obviously, and as noted earlier, such perceived contradictions rely on taking quite seriously our measurement of "quantity." It is possible that the easing of liquidity constraints allows firms to buy a different quality mix of tracts than they otherwise could. Similarly, a more subtle interpretation of the empire-building model could be that managers care about increasing scale through an increase in the "quality" of the projects they undertake. In the analysis below, we will however find no evidence that higher cash flow leads firms to bid on "better" tracts, either as measured based on the ex-ante characteristics of these tracts or based on their ex-post productivity.
} 
We focus on all bids in Panel A of Table 6 and on the sub-sample of winning bids in Panel B. The 2 panels follow the same structure, except for the last column of Panel B. All regressions in Table 6 include, in addition of cash flow, Tobin's Q, firm fixed effects and year fixed effects. Also, standard errors are estimated accounting for the correlation of the error term at the firm-level.

As a benchmark, column 1 shows that, absent any tract-level controls, a 1 percent increase in cash flow increases bid price per acre by between .11 (Panel A) and .16 percent (Panel B). In column 2, we add as a control the per barrel spot price of oil in the month the tract was auctioned off. ${ }^{20}$ Interestingly, there is a strong positive correlation between oil price at auction time and bid price, with a 1 percent increase in oil price raising bid price per acre by about .4 percent. The addition of this control however does not affect the relationship between bid price and cash flow.

In column 3, we further control for a set of tract-level characteristics capturing information that is available to the bidders at the time of bidding and that is likely to be correlated with the expected productivity of the tract. First, we control for the size of the lease, which we measure in number of acres. It is a well-known fact from previous work that larger tracts are on average less likely to be productive and tend to sell at a lower price (Hendricks and Porter 1996). Second, we control for the minimum and maximum depth of the tract. Everything else equal, tract depth is likely to be negatively correlated with expected profits as exploration and extraction costs increase with depth. Finally, also computable by firms prior to bidding on a given tract is the observed productivity on previously auctioned off tracts that are located in the same geographic area. We compute this area-specific productivity measure based on the MMS data. For a given lease located within a given area (referred to as "county" in the MMS data) and auctioned off at a given date, we compute the fraction of productive tracts among all the tracts that were auctioned off in that area prior to that date. ${ }^{21}$

As expected, larger tracts sell at a discount. A one percent increase in tract size leads to about a .25 percent drop in price. We also find (not reported in the table) that lower bids are recorded for deeper tracts. Also, there is a strong positive correlation between bid price and observed past productivity in a given area, everything else equal. Most important for our purpose, though, the inclusion of these three sets of controls has no effect on the estimated price-cash flow sensitivity.

In column 4, we further add controls for lease-specific contract characteristics. These include dummies for royalty rate, rental rate and length of lease. The inclusion of these additional controls somewhat lowers

\footnotetext{
${ }^{20}$ This monthly time series, titled "Spot Oil Price: West Texas Intermediate," was obtained from Dow Jones Energy Service.

${ }^{21}$ We prefer this measure to the inclusion of county fixed effects. Indeed, this measure is by definition only backward-looking while county effects would be both backward- and forward-looking. We however obtain qualitatively similar results if we include county fixed effects instead.
} 
the point estimate on cash flow. However, the point estimate stays positive and statistically unchanged.

Columns 5 and 6 respectively replicate columns 1 and 4 but spline the cash flow variable into three groups, allowing for the price-cash flow sensitivity to differ in the low, medium and high cash flow ranges. As before, we find that the positive association between price and cash flow is concentrated in the medium cash flow range.

Column 7 replicates column 6 but allows for the bid price-oil price relationship to vary by firm. The countervailing hypothesis we mean to test for here is the possibility that the firms in our sample may be differentially affected by variation in the price of oil. For example, a given firm may have a 100 percent of its activities in the oil business while another firm may have a lower fraction of its activities in that business. One may expect these 2 firms to respond differentially to a given increase in the price of oil. By allowing for interactions between the firm fixed effects and oil price, we account for such possible differences across firms. As our findings in column 7 indicate, though, the inclusion of these additional controls leaves the estimated relationship between bid price and cash flow economically and statistically unchanged.

Finally, we assess the robustness of our results to controlling for another tract characteristic that is likely to be even more informative about expected tract quality than the physical characteristics discussed above: the bid placed by the next highest bidder. In the last column of Panel B, we replicate columm 6 of that panel but further control for the logarithm of the second highest bid on that lease, when such a second highest bid exists. If no second bid exists, we assume the logarithm of the second highest bid to be zero; of course, we also include a dummy variable to identify these sole bidder auctions. As might have been expected, the second highest bid is very predictive of the winning bid, everything else equal. But its inclusion in the model does not statistically significantly alter the bid price-cash flow relationship. In other words, when cash flow rises, bidders are not only bidding more per acre for observationally equivalent tracts, they are also bidding more relative the next highest bidder.

An alternative way to approach the issues discussed in Table 6 is to ask whether cash-rich firms are systematically bidding on different kinds of tracts. Table 7 follows this alternative approach by directly relating tract-level characteristics to firm-level cash flow. All regressions in Table 7 control for Tobin's Q, firm and year fixed effects. We also include the monthly price of oil in even columns and interactions between firm fixed effects and the monthly price of oil in odd columns. As in all other tables, standard errors are computed allowing for clustering of the error term at the firm level.

The dependent variable in columns 1 and 2 is tract size (measured in number acres). We see that cash-rich firms do not systematically bid on smaller tracts, which are expected to be of higher quality. In columns 3 and 4, we ask whether cash-rich firms are more likely to bid on tracts located in counties 
where they already have a strong presence. If this were true, one might argue that these firms may have lower exploration and/or extraction costs, which may justify the higher bids. For a given firm bidding at a given date on a given tract located in a given county, we construct based on the MMS data the number of leases won by that firm in that county prior to that date. We also control in these regressions for the total number of leases auctioned off in that county prior to that date. We do not find any systematic evidence of cash-rich firms disproportionately bidding in areas where they are already engaged in more activity.

In columns 5 and 6 , we ask whether cash-rich firms bid more systematically on tracts located in areas where higher success rates have been recorded in the past. We find no evidence for this. In fact, the point estimate on cash flow in these regressions is negative (even though statistically insignificant).

The dependent variable in columns 7 and 8 is the number of separate bids recorded for that tract. Our goal here is to examine whether cash-rich firms are engaging in more differentiating behavior by bidding on tracts that other firms are less likely to target. Interestingly, we find the exact opposite. When firms are cash-rich, they are more likely to bid on tracts that other firms are also targeting. While we cannot provide a definitive interpretation for this finding, one conjecture is that this reflects a higher reliance on public information. Managers at cash-rich firms may spend less time trying to acquire private information about the leases to be auctioned off (possibly for agency reasons) and instead herd on the behavior of other bidders. ${ }^{22}$

Finally, in columns 9 and 10, we examine whether cash-rich firms systematically bid on tracts that other firms are willing to pay more for. Focusing on the sub-sample of leases that attracted more than one bid (which we know to be a selected sample from our findings in columns 7 and 8), we regress the second highest bid for that tract on the winning firm's cash flow. We find no relationship.

In summary, these results suggest that cash-rich firms pay more for leases that appear equivalent on a set of publicly observable quality dimensions. In addition, the fact that cash-rich firms are more likely to bid on leases that attract other bidders is a priori hard to reconcile with the idea that these firms are relying more on private information to guide their bidding behavior. However, these facts per se are not enough to say anything conclusive about how cash flow relates to the eventual productivity of these leases. It may still be that the leases bid on when cash flow is high are intrinsically better along some unobservable dimensions. Alternatively, even if these leases are not intrinsically better, perhaps positive shocks to cash flow are associated with a higher intrinsic "ability" to find oil. The true test of whether the increased expenditures reflect profitable investments or dissipated cash can only come from directly looking at the

\footnotetext{
${ }^{22} \mathrm{An}$ increased reliance on public information need not be a violation of profit maximization if tracts attracting a lot of bidders are also on average more productive. The definitive test will come from assessing the eventual productivity of the tracts bought when cash flow is high.
} 
productivity of these tracts. This is the question we now turn to.

\subsection{Tract-Level Productivity and Cash Flow}

As we discussed above, included in the MMS data is an indicator for whether or not a given tract ended up being declared productive before the lease expiration date. ${ }^{23}$ In Table 8 , we relate this productivity variable to bid price and cash flow. ${ }^{24}$

In column 1, we regress a dummy variable for whether the tract was found productive on bid price per acre, firm fixed effects and year fixed effects. ${ }^{25}$ We find that a higher bid price per acre is predictive of the eventual productivity of a tract. This is a well-known fact in this literature. A one percent increase in bid price per acre increases the likelihood that the lease will be productive by about .09 percentage point.

Column 2 of Table 8 presents the IV equivalent of the OLS regression in column 1. More precisely, we instrument bid price per acre with cash flow at the time of the bid, using the splined specification described above. This IV regression allows us to ask whether cash flow driven increases in bid price per acre are also positively related to tract productivity. We find no evidence for this. The point estimate on bid price in column 2 is in fact negative and marginally significant $(p=.097)$. A one percent increase in bid price per acre due to a positive shock to cash flow reduces the likelihood that the tract will be productive by about .13 percentage point. Column 3 presents the reduced form regression equivalent to the IV regression in column 2. This reduced form regression shows that it is in the medium cash flow range that positive shocks to cash flow are associated with lower productivity. There is no relationship between cash flow and productivity in the bottom and top cash flow ranges.

The remaining columns of Table 8 assess the robustness of these first results to controlling for additional lease- and firm-level characteristics. OLS regressions are in even columns; IV regressions are in odd columns. In columns 4 and 5, we add a control for the price of oil in the month the lease was auctioned off. Columns 6 and 7 further control for tract-level characteristics (minimum and maximum depths of the tract, size of tract). Finally, columns 8 and 9 further add to the list of controls contract characteristics (dummies for royalty rate, rental rate and length of lease) and Tobin's Q.

\footnotetext{
${ }^{23}$ More specifically, the MMS data include a variable called "lease qualifying date," which is defined as the day, month, and year that a lease is determined capable of production in paying quantities as established by the Minerals Management Service. We define as "non-productive" those leases that do not have a lease qualifying date.

${ }^{24}$ An alternative approach would be to explicitly calculate a tract level ex post return on investment as in Hendricks, Porter and Boudreau (1987). We chose against this strategy since we are primarily interested in how this return varies with firm cash flow and not with the level of that return. For that purpose, our binary variable (and the output data used below for the subset of productive tracts) should capture much of the variation. This is especially true since the costs of exploration and extraction that would have to be used to generate such a return calculation depend mostly on observable tract and timing characteristics that we can directly control for.

${ }^{25}$ We estimate a linear probability model. Similar results are found using tobit or probit models instead.
} 
The OLS and IV estimates of the coefficient on bid price per acre are remarkably stable across all these different specifications. Interestingly, bid price per acre is still a strong positive predictor of productivity even after the addition of all of these controls. This indicates that there is residual information in the price data and thus further reinforces the need to perform the productivity-cash flow sensitivity analysis reported in this table. Indeed, the positive price-cash flow sensitivity observed earlier may in part reflect some private information cash-rich firms have about tract quality. The IV results in this table show no evidence that this is the case.

In summary, the average probability of finding mineral resources in a tract does not increase, and in fact might well decrease, with cash flow. Recall from Section 4 that this could in principle happen under all three interpretations of the investment-cash flow sensitivity if there are scale effects. Indeed, profit

maximization only implies that $\frac{\partial p * N}{\partial C F}=p_{C F} * N+N_{C F} * p>0$. However, we have seen earlier that there is no quantity response to cash flow, i.e. $N_{C F} \approx 0$. If $N_{C F} \approx 0$, then profit maximization must imply that $p_{C F}>0$, which we find no evidence for in the data. Thus, we view this combined set of results to be in contradiction with profit maximization. Put simply, our results so far state that firms, when cash rich: (i) spend more on buying tracts, (ii) do not buy more tracts and (iii) buy tracts that are not more productive on average.

\subsection{Number of Productive Tracts and Cash Flow}

A more direct way to test for a violation of profit maximization is to estimate the relationship between cash flow and the total number of productive tracts (rather than average productivity). In Table 9, we investigate how $p * N$ varies with cash flow. We regress total number of productive exploration projects on firm cash flow in the year these projects were undertaken. In the first 2 columns of Table 9 , we simply sum all productive leases undertaken. In the last 4 columns, we weight each lease by the firm's fraction of ownership in this lease. Columns 1 and 3 estimate a linear regression model; columns 2 and 4 estimate a splined regression model. Each regression includes Tobin's Q, firm fixed effects and year fixed effects. Standard errors are computed allowing for clustering of the error term at the firm level.

While we know from Table 4 that total spending increases with cash flow, we find no evidence that total revenue (as proxied by the number of productive tracts) increases with cash flow. In fact, the point estimate on cash flow is negative, but not statistically significant (columns 1 and 3 ). When we replace the linear model with a splined specification, we find that the negative correlation is again concentrated in the middle cash flow range. 


\subsection{Total Resources Found in Productive Tracts and Cash Flow}

In both the theoretical framework and the empirical work so far, we have assumed that the quantity of minerals found in productive tracts does not systematically change with cash flow. Is this a realistic assumption? One could imagine that cash-rich firms bid on tracts that are riskier: less likely to be productive on average, but bigger amounts of resources found when the tract is productive. To analyze this question, we turn in Table 10 to lease-level production data.

We could only obtain such production data for leases auctioned off from 1978 on. For each of these productive leases, we can measure reported gas production (columns 1 to 4 ) and oil production (columns 5 to 8). We regress the logarithms of these production figures on bid price and cash flow, controlling for year and firm fixed effects, as before. The regressions also include a control for the price of oil in the month the lease was auctioned off (columns 1,2,5 and 6) or interactions between the price of oil and firm fixed effects (columns 3, 4, 7 and 8). Finally, since production on the leases in this sample started at different points in time, one must also account for the length of time since production started. We implement this by including dummy variables for the number of months a tract has been under production.

Two interesting results emerge from Table 10. First, for both gas and oil outputs, bid price is an economically small and statistically insignificant predictor of actual production amount (columns 1, 3, 5 and 7). The point estimates on bid price are in fact negative in all these regressions. In other words, while bid price predicts whether a given tract will be productive, it does not predict the amount of minerals found conditional on productivity. This is consistent with previous findings and suggests that bidders are not able to accurately predict the amount of resources under the ground. ${ }^{26}$ Second, cash flow does not predict amount of gas found. The coefficients are small and insignificant (columns 2 and 4). For oil production, the estimated coefficient on cash flow is negative in both columns 6 and 8 and statistically significant in column 6 . This is quite the opposite of the risk-return explanation outlined at the beginning of this section as an alternative interpretation for our findings.

\subsection{Results Over Time}

These results as a whole are suggestive of an agency problem in the oil industry. Yet our data stretches a wide period: 1963 to 1999. During this time period, numerous commentators have argued that governance has improved in this industry. Specifically, the takeover wave of the 1980s is purported to have led to tighter governance. This naturally leads one to ask whether our findings vary over time. To answer this

\footnotetext{
${ }^{26}$ Geologically, the total amount of minerals found depends on the depth of the well below the ground as well as its topology well below the earth, both of which being hard to measure before exploration.
} 
question, we pick a rather arbitrary cutoff date (1985) and re-examine our main findings before and after this cutoff. ${ }^{27}$ It is obviously worth noting that many other factors besides governance may have changed across these two time periods (such as technology, for example). In this regard, we view these regressions as mainly descriptive, and certainly not causal.

We first examine whether and how the bidding results of Tables 6 change before and after 1985. As Table 11 indicates, there is a remarkable congruence across the two time periods. By this metric, at least, governance has not improved: cash flow still strongly predicts bid price. In Table 12, we examine whether and how the productivity results of Table 8 change before and after 1985. The findings in this table, while somewhat noisy, do appear to suggest some contrasting patterns across the two time periods. Specifically, the negative productivity findings are concentrated in the pre-1985 period. Hence, there is some suggestive evidence that firms bidding on these leases may have altered their behavior after the mid-1980s, in a way that is consistent with more profit maximization, and possibly due to an improvement in corporate governance.

\section{Interpretation}

\subsection{Confounds}

Our findings in Section 5, interpreted through the simple framework of Section 4, support a free cash flow interpretation of the investment-cash flow sensitivity in this industrial setting. The framework proposed in Section 4 was however quite stylized. One may therefore ask whether any complication to that framework may alter the current interpretation of our findings. We consider three potential complications. First, we discuss the possible impact of introducing imperfect competition (or collusion) amongst bidders. Second, we consider complications to the firm's objective function. Finally, we consider whether managerial overconfidence might better fit our findings.

The stylized framework in Section 4 abstracts from the details of the bidding process. This is valid as long as a bidder's cash flow does not affect this bidding process, which would be the case if each auction had numerous competing bidders. But, as we discussed in Section 2, most of the auctions in our data have very few bidders, which is why firms win roughly $\frac{7}{9}$ of all tracts they place bids on. ${ }^{28}$ Could collusive bidding explain our findings? It would be possible to rationalize that higher cash flow gives a firm a greater financial incentive to deviate from a collusive equilibrium. For example, cash-rich firms may be in a position where

\footnotetext{
${ }^{27}$ Very similar results follow if we choose any other date in the 1980s as the cutoff.

${ }^{28}$ Allegations of bidder collusion are sometimes made about oil and gas lease bidding. See for example Bajari and Summers (2002) for an empirical discussion of collusion in such auctions.
} 
they have a higher chance to win a bidding war with their competitors. This could explain one of our results, i.e. the rise in bid price when cash flow increases (Table 6). This could also explain the fact that high cash flow firms are more likely to bid on tracts that receive other independent bids (Table 7). Yet, if a firm is rationally deviating from a collusive equilibrium, it should do so to increase its profits. We have found, however, that the marginal tract bought when cash flow increases is not more productive (Table 8). We find this last finding much harder to reconcile with a rational collusion breakdown interpretation.

Our stylized framework also assumes that tract returns are independent, meaning that the productivity of a tract completely captures the returns to investing in that tract. Yet interdependencies between tracts can potentially exist. Firms may learn from their success (or not) on one tract which other tracts to bid on (or not to bid on). This could potentially explain our productivity results if high cash flow leads firms to experiment more, for example by bidding on tracts further away from the areas they know best. The higher failure rate on such tracts may be offset by the higher profits they experience on future bids once they have identified new productive areas. This interpretation, while fitting some of our basic facts, does not fit several others. First, recall that in Table 7, we examined the relationship between a firm's cash flow and the characteristics of the tracts this firm bids on. There (columns 3 and 4), we found no systematic relationship between firm cash flow and number of neighboring tracts (to the tract bid on) that are owned by the firm. Second, this interpretation suggests that higher cash flow today should be predictive of higher productivity among tracts bought in later years. We formally tested this idea. Specifically, we replicated the reduced form specifications of Table 8 using as a dependent variable the productivity of tracts bought in year $t+5$ (while cash flow was still measured in year $t$ ). We found no systematic relationship between tract productivity and cash flow in this case. ${ }^{29}$ This suggests that experimentation and between-tract externalities could not easily explain our results.

Finally, might managerial overconfidence help explain our pattern of findings? ${ }^{30}$ Perhaps high cash flow induces managers to be overconfident about their abilities to find the right tract of land, causing them to bid more on tracts that end up not being more productive. ${ }^{31}$ It is unclear under this explanation, however, why managers do not bid on more tracts or buy more tracts. If they felt a greater ability to pick winners, would they not take advantage of this ability by buying more tracts or expanding in some way the scale of

\footnotetext{
${ }^{29}$ For example, a replication of column 3 of Table 8 led to the following coefficients (and standard errors) on the cash flow variables: cash flow-spline 1: -.008 (.022); cash flow-spline 2: -.013 (.068); cash flow-spline 3: -.056 (.060). Note also that we found no significant relationship between bid price and cash flow under this alternative lag structure. In other words cash flow in year $t$ does not predict bid price per acre in year $t+5$.

${ }^{30}$ Kahneman and Lavallo (1993) provide a useful psychological perspective on overconfidence. Roll (1986), Heaton (2002), Hackbarth (2003) and Malmendier and Tate (forthcoming) provide some discussions and evidence within the field of corporate finance.

${ }^{31}$ Of course, one could also have said that overconfidence should lead them to bid less since they might also be overconfident about their probability of winning.
} 
operations? The lack of a quantity response, we believe, makes the overconfidence story less plausible in this setting.

Thus, while the framework we propose in Section 4 is quite stylized, the complications discussed above do not clearly lead us to alter the interpretation of our findings. We believe that these findings are best explained by a "quiet life" agency model: managers use cash to make their work easier, outbidding competitors on tracts they are also vying for rather than looking hard to find productive tracts that others are not bidding on. While a more detailed quiet life model is hard to test without greater organizational data, we can speculate about what one might look like. When cash flow rises, top management may increase budgets throughout the organization or be more lenient with budgetary requests. This in turn gives lower-level managers greater slack. In an empire-building model, these lower-level managers may use that slack to buy more tracts and expand the scale of operations. In a quiet life model, they may use that slack to save on their private costs of effort. For example, instead of engaging in time-consuming research to discover which tracts look more attractive, they may instead pick tracts that are publicly thought to be attractive and outbid their competition on these tracts. Instead of risking the chance of failure (and hence of having to start the search process again), they may overpay to ensure that they win a given auction. The key feature of this model is that managers' goal is to reduce effortful activities.

\subsection{Generalization}

Can these results generalize to other industries or to the economy as a whole? Of course, every industry has its own features so it is unlikely that any single industry study could be used to paint a "general" picture. Nevertheless, we find it useful to highlight a few distinctive features of the oil bidding process. This may in turn help predict in which other contexts one could expect similar results.

A first important feature, which we have just discussed, is that lower-level managers make most of the specific investment decisions in this context. Except at smaller firms, top management is not involved in the details of the exploration and bidding activities. ${ }^{32}$ Thus our results may more likely generalize to other investment projects decided upon lower down in the corporate hierarchy rather to ones (such as acquisitions or mergers) decided upon at the top of the hierarchy. ${ }^{33}$

The lack of a quantity response is important to the "quiet life" interpretation we have proposed for our findings. Could this be driven by the limited number of tracts that go for sale in every period? At the extreme, one could imagine that this indeed contributes to the lack of a quantity response: it is harder

\footnotetext{
${ }^{32}$ Though, of course, top management may set the overall budget for these activities.

${ }^{33}$ See Bertrand and Mullainathan 2003, however, for evidence on "quiet life"-type behavior even for large investment decisions (such as plant openings and closures) likely made at the top of the hierarchy.
} 
to expand the number of tracts explored if the aggregate number of tracts for sale is capped. In practice, though, this is unlikely to be a binding constraint since a large fraction of tracts goes un-bought in every single sale. In other words, bidders could easily expand the scale of their operations by bidding on more tracts, many of which would not be bid on and go unsold. ${ }^{34}$ Also, it is important to note that aggregate scale constraint is a feature of investment in many other industries; it is simply more transparent here because of the bidding process. Aggregate demand or limited resources (e.g. natural or land) all could contribute to a similar constraint on the number of investment projects in other industries.

Finally, this is a remarkably cash rich industry. Everything else equal, liquidity constraints are therefore likely to be less important here than in other settings. While this does not undercut the evidence we have presented, it does leave open the possibility that liquidity constraints may play a more central role in other industrial sectors.

\section{Conclusion}

As a whole, our findings in this paper appear to support a free cash flow model of the investment-cash flow sensitivity in the oil industry, with firms spending more on investment projects when cash flow is high but not generating additional revenues from this additional spending. The specific form of the additional spending (through a price margin rather than a quantity margin, and by bidding more systematically on tracts that have also been identified and targeted by other bidders) is most consistent with a version of the free cash flow model where richer managers prefer to lead a "quiet life" rather than to build "empires." We conjecture that the "quiet life" behavior exhibited in this industry takes the form of lower-level managers expanding less personal effort in screening which tracts to bid on when their budget increases (because of higher cash flow), and instead using cash to outbid competitors on tracts for which there is greater public information. Obviously, further testing of this specific corporate response to higher cash flow would require much finer information on the specific allocation of resources and responsibilities within firms. Such detailed internal budgeting and organizational data is unfortunately not widely available at this point in time.

Finally, our results also suggest some behavioral changes over time. These changes are consistent with investment decisions being more in line with profit maximization after the mid-1980s, a period over which numerous observers suggested that corporate governance in the oil industry improved.

\footnotetext{
${ }^{34}$ One could in principle argue that the number of "quality" tracts is capped, something we have no way of evaluating.
} 


\section{References}

Alti , Aydogan, 2003, "How Sensitive is Investment to Cash Flow when Financing is Frictionless?" Journal of Finance, 58, 707-722.

Bajari, Patrick and Garrett Summers, 2002, "Detecting Collusion in Procurement Auctions," Antitrust Law Journal, 70(1), 143-170.

Bertrand, Marianne and Sendhil Mullainathan, 2003, "Enjoying the Quiet Life? Corporate Governance and Managerial Preferences," Journal of Political Economy, 111 (5), 1043-1075.

Bertrand, Marianne, Esther Duflo and Sendhil Mullainathan, 2004, "How Much Should We Trust Differencesin-Differences Estimates? Quarterly Journal of Economics, 119 (1), 249-275.

Caballero, Ricardo, 1999, "Aggregate Investment," in Handbook of Macroeconomics, edited by John B. Taylor and Michael Woodford, North Holland.

Erickson, Timothy and Toni Whited, 2000, "Measurement Error and the Relationship between Investment and Q," Journal of Monetary Economics, 108 (51), 1027-1057.

Fazzari, Steven R., R. Glenn Hubbard and Bruce Petersen, 1988, "Financing Constraints and Corporate Investment," Brookings Papers on Economic Activity, 1, 141-195.

Heaton, James Breckinridge, 2002, "Managerial Optimism and Corporate Finance," Financial Management, $31,33-45$.

Hackbarth, Dirk, 2003, "Managerial Optimism, Overconfidence, and Capital Structure Decisions," Working Paper, University of California, Berkeley.

Hendricks, Kenneth, Robert H. Porter and Bryan Boudreau, 1987, "Information, Returns, and Bidding Behavior in OCS Auctions: 1954-1969," The Journal of Industrial Economics, 35(4), 517-542.

Hendricks, Kenneth and Robert H. Porter, 1996, "The Timing and Incidence of Exploratory Drilling on Offshore Wildcat Tracts," American Economic Review, 86, 388-407.

Hendricks, Kenneth, Joris Pinske and Robert H. Porter, 2003, "Empirical Implications of Equilibrium Bidding in First-Price, Symmetric, Common-Value Auctions," Review of Economic Studies, 1, 115145.

Hicks, John, 1935, "Annual Survey of Economic Theory: The Theory of Monopoly," Econometrica, 3, 1-20.

Jensen, Michael C., 1986, "Agency Costs of Free Cash Flow, Corporate Finance, and Takeovers," American Economic Review, 76, 323-329.

Kahneman, D. and D. Lovallo, 1993, "Timid Choices and Bold Forecasts: A Cognitive Perspective on Risk Taking," Management Science, 39, 17-31.

Kaplan, Steven N. and Luigi Zingales, 1997, "Do Investment-Cash Flow Sensitivities Provide Meaningful Measures of Financing Constraints?" Quarterly Journal of Economics, 112, 169-215.

Lamont, Owen, 1997, "Cash Flow and Investment: Evidence from Internal Capital Markets," Journal of Finance, 52, 57-82.

Malmendier, Ulrike, and Geoffrey Tate, "CEO Overconfidence and Corporate Investment," Journal of Finance, forthcoming.

Poterba, James, 1988, "Comments on Fazzari, Hubbard and Petersen," Brookings Papers on Economic Activity, 1, 200-204. 
Rauh, Joshua D., "Investment and Financing Constraints: Evidence from the Funding of Corporate Pension Plans," Journal of Finance, forthcoming.

Roll, Richard, 1986, "The Hubris Hypothesis of Corporate Takeovers," Journal of Business, 59, 197-216.

Shin, Hyun-Han and Rene Stultz, 1998, "Are Internal Capital Markets Efficient?," Quarterly Journal of Economics, 113, 531-553.

Stein, Jeremy, 2003, "Agency, Information, and Corporate Investment," in Handbook of the Economics of Finance, edited by George Constantinides, Milton Harris, and Rene Stulz, North-Holland. 


\section{Table I: Bid-Level Summary Statistics ${ }^{a}$}

\begin{tabular}{|c|c|c|}
\hline Sample: & All Bids & Winning Bids \\
\hline Bid price per acre & $\begin{array}{c}1753.738 \\
(5516.353)\end{array}$ & $\begin{array}{c}1822.439 \\
(6219.530)\end{array}$ \\
\hline Log (bid price per acre) & $\begin{array}{c}5.532 \\
(1.889)\end{array}$ & $\begin{array}{c}5.384 \\
(1.907)\end{array}$ \\
\hline Tract size (in acres) & $\begin{array}{l}5211.089 \\
(941.939)\end{array}$ & $\begin{array}{l}5224.442 \\
(995.343)\end{array}$ \\
\hline Productive? $(\mathrm{Y}=1)$ & $\begin{array}{c}.306 \\
(.461)\end{array}$ & $\begin{array}{c}.240 \\
(.427)\end{array}$ \\
\hline Log (total assets) & $\begin{array}{c}9.083 \\
(1.689)\end{array}$ & $\begin{array}{c}9.191 \\
(1.654)\end{array}$ \\
\hline Log (cash flow) & $\begin{array}{c}-1.610 \\
(.423)\end{array}$ & $\begin{array}{c}-1.635 \\
(.415)\end{array}$ \\
\hline Lagged Tobin's Q & $\begin{array}{l}1.166 \\
(.561)\end{array}$ & $\begin{array}{l}1.176 \\
(.600)\end{array}$ \\
\hline Sample size & 24363 & 16410 \\
\hline
\end{tabular}

${ }^{a}$ Notes:

1. The unit of observation is a bid (placed by a given company on a given lease). This table presents means and standard deviations (in parentheses) for several bid, tract and firm-level characteristics. The sample in column 2 is all bids placed between 1963 and 1999 by companies (or subsidiaries of companies) covered in COMPUSTAT. The sample in column 3 is all winning bids placed between 1963 and 1999 by companies (or subsidiaries of companies) covered in COMPUSTAT. Sample sizes reported at the bottom of columns 2 and 3 are maximum sample sizes: not all variables are available for each observation. Data sources: Mineral Management Services and COMPUSTAT (see Section 3 for details).

2. All nominal figures are deflated using the CPI (base year is 2000). 


\section{Table II: Firm-Level Capital Expenditures, Cash Flow and Bidding ${ }^{a}$}

Panel A: Total Capital Expenditures-Cash Flow Correlation

\section{Dep. var.: Total Capital Expenditures}

All Years All Years Bidding Years Winning Years

Cash flow

$$
.448
$$

.421

$(.046)$

.369

$(.069)$

.366

.141

.070

$(.032)$

.072

(.048)

Yes

Yes

1017

Year F.E.?

Firm F.E.?

Yes

Yes

2298

Yes

Sample size

.51

.51

.59

Yes

960

Adjusted $\mathrm{R}^{2}$

Panel B: Bidding-Total Capital Expenditures Correlation

Dep. Var.:

Capital expenditures

$$
.047
$$

Yes

Yes

2418

.51
.044

(.016)

Yes

Yes

2418

.53
Amount Bid

Yes

Yes

1041

.70
Amount Won

Yes

Yes

980

.64

\section{${ }^{a}$ Notes:}

1. Panel A presents regressions of total capital expenditures on cash flow at the firm level. Panel B presents regressions of bidding probabilities, winning probabilities and total amount bid and won at the firm level. The firms included in the sample are those COMPUSTAT firms that have placed at least one bid in the MMS data between 1963 and 1999. Observations for these firms are included for all years in columns 1 and 2, only bidding years in column 3 and only winning years in column 4 . Data sources: Mineral Management Services and COMPUSTAT (see Section 3 for details).

2. Total capital expenditures, cash flow, amount bid and amount won are all deflated by net property, plant and equipment at the beginning of the fiscal year. All are expressed in logarithms.

3. Standard errors are corrected for clustering of the error term at the firm-level. 
Table III: Predicted Effect of Cash Flow: Different Theoretical Models

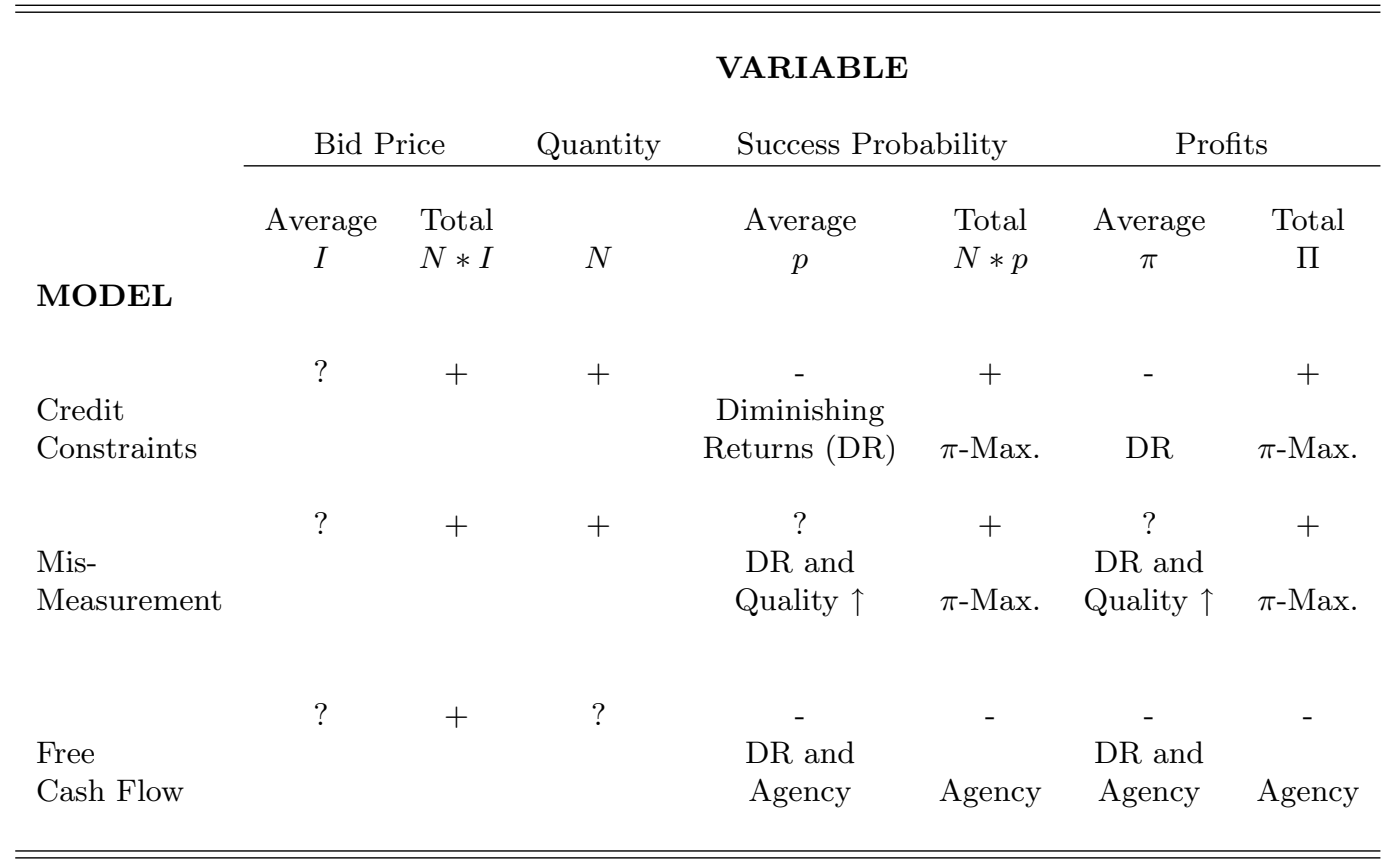




\section{Table IV: Firm Level Bidding ${ }^{a}$}

\begin{tabular}{|c|c|c|c|c|}
\hline \multirow[t]{2}{*}{ Dep. Var: } & \multicolumn{2}{|c|}{ Amount Bid } & \multicolumn{2}{|c|}{ Amount Won } \\
\hline & $(1)$ & $(2)$ & $(3)$ & $(4)$ \\
\hline Cash flow & $\begin{array}{c}.383 \\
(.129)\end{array}$ & & $\begin{array}{c}.381 \\
(.132)\end{array}$ & \\
\hline Cash flow-spline 1 & & $\begin{array}{c}.084 \\
(.159)\end{array}$ & & $\begin{array}{c}.007 \\
(.155)\end{array}$ \\
\hline Cash flow-spline 2 & & $\begin{array}{c}.898 \\
(.346)\end{array}$ & & $\begin{array}{c}1.04 \\
(.370)\end{array}$ \\
\hline cash flow-spline 3 & & $\begin{array}{c}.579 \\
(.379)\end{array}$ & & $\begin{array}{c}.634 \\
(.393)\end{array}$ \\
\hline Tobin's Q & $\begin{array}{c}.029 \\
(.089)\end{array}$ & $\begin{array}{c}-.01 \\
(.102)\end{array}$ & $\begin{array}{c}.060 \\
(.072)\end{array}$ & $\begin{array}{c}.006 \\
(.093)\end{array}$ \\
\hline Year F.E.? & Yes & Yes & Yes & Yes \\
\hline Firm F.E.? & Yes & Yes & Yes & Yes \\
\hline Sample size & 1031 & 1031 & 973 & 973 \\
\hline Adjusted $\mathrm{R}^{2}$ & .69 & .69 & .636 & .639 \\
\hline
\end{tabular}

\section{${ }^{a}$ Notes:}

1. The table presents regressions of total amount bid and total amount won on cash flow at the firm level. The firms included in the sample are those COMPUSTAT firms that have placed at least one bid in the MMS data between 1963 and 1999. Observations for these firms are included only for bidding years in columns 1 and 2, and only for winning years in columns 3 and 4. Data sources: Mineral Management Services and COMPUSTAT (see Section 3 for details).

2. Cash flow, amount bid and amount won are all deflated by net property, plant and equipment at the beginning of the fiscal year. All are expressed in logarithms. We use a linear spline of the cash flow variable in columns 2 and 4. "Cash flow-spline 1", "cash flow-spline 2," and "cash flowspline 3" respectively correspond to the 1ow cash flow levels (below the 33rd percentile of the cash flow distribution), the medium cash flow levels (between 33rd and 66th percentile of the cash flow distribution) and the high cash flow levels (above 66th percentile of the cash flow distribution).

3. Standard errors are corrected for clustering of the error term at the firm-level. 


\section{Table V: Price versus Quantity Firm Level Data ${ }^{a}$}

\section{Panel A: Price Effect}

Dep. Var.:

\section{Amount Bid/ Number of Tracts Bid On}

Cash flow-spline 1

Cash flow-spline 2

Cash flow-pline 3

Tobin's Q

Year F.E.?

Firm F.E.?

Sample size

Adjusted $R^{2}$
Yes

Yes

1031

.862
Yes
Amount Won/ Number of Tracts Won

Yes

Yes Yes

$973 \quad 973$

\section{${ }^{a}$ Notes:}

1. Panel A presents regressions of total amount bid (total amount won) per bid on (won) tract on cash flow at the firm level. The firms included in the sample are those COMPUSTAT firms that have placed at least one bid in the MMS data between 1963 and 1999. Observations for these firms are included only for bidding years in columns 1 and 2, and only for winning years in columns 3 and 4 . Data sources: Mineral Management Services and COMPUSTAT (see Section 3 for details).

2. Cash flow, amount bid and amount won are deflated by net property, plant and equipment at the beginning of the fiscal year. Cash flow, amount bid per number of tracts bid on, and amount won per number of tracts won are all expressed in logarithms. We use a linear spline of the cash flow variable in columns 2 and 4. "Cash flow-spline 1", "cash flow-spline 2," and "cash flow-spline 3" respectively correspond to the 1ow cash flow levels (below the 33rd percentile of the cash flow distribution), the medium cash flow levels (between 33rd and 66th percentile of the cash flow distribution) and the high cash flow levels (above 66th percentile of the cash flow distribution).

3. Standard errors are corrected for clustering of the error term at the firm-level. 


\section{Table V (cont.): Price versus Quantity Firm Level Data ${ }^{a}$}

\section{Panel B: Quantity Effect}

Dep. Var.:

Bid On
Number of Tracts

Won
(4)

Cash flow-spline 1

$$
.083
$$

Cash flow .213

Cash flow-spline 2

Cash flow-spline 3

$$
-.231
$$

Tobin's Q

Year F.E.?

Firm F.E.?

Sample size

Adjusted $\mathrm{R}^{2}$

$\begin{array}{cc}\text { Yes } & \text { Yes } \\ \text { Yes } & \text { Yes } \\ 1031 & 1031 \\ .608 & .608\end{array}$

$\begin{array}{cc}\text { Yes } & \text { Yes } \\ \text { Yes } & \text { Yes } \\ 973 & 973 \\ .576 & .576\end{array}$

\footnotetext{
${ }^{a}$ Notes:
}

1. Panel B presents regressions of number of tracts bid on (won) on cash flow at the firm level. The firms included in the sample are those COMPUSTAT firms that have placed at least one bid in the MMS data between 1963 and 1999. Observations for these firms are included only for bidding years in columns 1 and 2, and only for winning years in columns 3 and 4. Data sources: Mineral Management Services and COMPUSTAT (see Section 3 for details).

2. Cash flow is deflated by net property, plant and equipment at the beginning of the fiscal year. Cash flow, number of tracts bid on and number of tracts won are all expressed in logarithms. We use a linear spline of the cash flow variable in columns 2 and 4. "Cash flow-spline 1", "cash flow-spline 2," and "cash flow-spline 3" respectively correspond to the 1ow cash flow levels (below the 33rd percentile of the cash flow distribution), the medium cash flow levels (between 33rd and 66th percentile of the cash flow distribution) and the high cash flow levels (above 66th percentile of the cash flow distribution).

3. Standard errors are corrected for clustering of the error term at the firm-level. 
Panel A: All Bids

\section{Dependent Variable: Bid Price Per Acre}

\begin{tabular}{|c|c|c|c|c|c|c|c|}
\hline & $(1)$ & $(2)$ & $(3)$ & $(4)$ & $(5)$ & (6) & $(7)$ \\
\hline Cash flow & $\begin{array}{c}.108 \\
(.049)\end{array}$ & $\begin{array}{c}.099 \\
(.049)\end{array}$ & $\begin{array}{c}.102 \\
(.048)\end{array}$ & $\begin{array}{c}.062 \\
(.045)\end{array}$ & & & \\
\hline Cash flow-spline 1 & & & & & $\begin{array}{l}.013 \\
(.060)\end{array}$ & $\begin{array}{l}.023 \\
(.053)\end{array}$ & $\begin{array}{l}.015 \\
(.054)\end{array}$ \\
\hline Cash flow-spline 2 & & & & & $\begin{array}{l}.503 \\
(.210)\end{array}$ & $\begin{array}{l}.512 \\
(.204)\end{array}$ & $\begin{array}{l}.513 \\
(.226)\end{array}$ \\
\hline Cash flow-spline 3 & & & & & $\begin{array}{l}.244 \\
(.244)\end{array}$ & $\begin{array}{l}-.117 \\
(.191)\end{array}$ & $\begin{array}{l}-.372 \\
(.198)\end{array}$ \\
\hline Tobin's Q & $\begin{array}{l}-.095 \\
(.044)\end{array}$ & $\begin{array}{l}-.102 \\
(.045)\end{array}$ & $\begin{array}{l}-.101 \\
(.045)\end{array}$ & $\begin{array}{l}-.092 \\
(.044)\end{array}$ & $\begin{array}{l}-.118 \\
(.052)\end{array}$ & $\begin{array}{l}-.083 \\
(.054)\end{array}$ & $\begin{array}{r}-.041 \\
(.05)\end{array}$ \\
\hline Monthly oil price & & $\begin{array}{c}.412 \\
(.102)\end{array}$ & $\begin{array}{c}.397 \\
(.122)\end{array}$ & $\begin{array}{c}.290 \\
(.108)\end{array}$ & & $\begin{array}{c}.280 \\
(.107)\end{array}$ & \\
\hline County success rate & & & $\begin{array}{l}.504 \\
(.11)\end{array}$ & $\begin{array}{l}.494 \\
(.093)\end{array}$ & & $\begin{array}{l}.493 \\
(.093)\end{array}$ & $\begin{array}{l}.458 \\
(.095)\end{array}$ \\
\hline Tract size & & & $\begin{array}{l}-.254 \\
(.04)\end{array}$ & $\begin{array}{l}-.241 \\
(.037)\end{array}$ & & $\begin{array}{l}-.241 \\
(.037)\end{array}$ & $\begin{array}{l}-.240 \\
(.038)\end{array}$ \\
\hline Tract depth? & No & No & Yes & Yes & No & Yes & Yes \\
\hline $\begin{array}{l}\text { Contract characteristics? } \\
\text { Firm F.E.* }\end{array}$ & No & No & No & Yes & No & Yes & Yes \\
\hline Monthly oil price? & No & No & No & No & No & No & Yes \\
\hline Year F.E.? & Yes & Yes & Yes & Yes & Yes & Yes & Yes \\
\hline Firm F.E.? & Yes & Yes & Yes & Yes & Yes & Yes & Yes \\
\hline Sample Size & 21340 & 20972 & 20188 & 19184 & 21340 & 19184 & 19184 \\
\hline Adjusted $\mathrm{R}^{2}$ & .700 & .701 & .710 & .717 & .700 & .717 & .725 \\
\hline
\end{tabular}

\section{${ }^{a}$ Notes:}

1. The sample in Panel A are all bids by COMPUSTAT firms between 1963 and 1999. The sample in Panel B are all winning bids by COMPUSTAT firms between 1963 and 1999. Data sources: Mineral Management Services and COMPUSTAT (see Section 3 for details).

2. Tract depth includes control for the minimum and maximum depth of the tract. Contract characteristics include dummy variables for royalty rate, rental rate and length of lease. Monthly oil price refers to the price of a barrel of oil in the month the tract was auctioned off. Country success rate is defined as the fraction of productive tracts among all the tracts that were auctioned off in that county prior to that tract. " $2^{\text {nd }}$ highest bid" refers to the second highest bid on the tract. It is set to zero if there are no other bids. "Sole bidder" is a dummy variable that equals 1 if there were no other bids.

Notes continued on next page. 
Panel B: Winning Bids

\section{Dependent Variable: Bid Price Per Acre}
(1)
(2)
(3)
(4)
(5) (6)
(7)
(8)

Cash flow

$\begin{array}{llll}.159 & .154 & .159 & .117\end{array}$

$\begin{array}{llll}(.062) & (.064) \quad(.059) \quad(.049)\end{array}$

Cash flow-spline 1

Cash flow-spline 2

Cash flow-spline 3

\begin{tabular}{|c|c|c|c|c|c|c|c|}
\hline & & & & $\begin{array}{c}.069 \\
(.063)\end{array}$ & $\begin{array}{c}.078 \\
(.057)\end{array}$ & $\begin{array}{l}.054 \\
(.06)\end{array}$ & $\begin{array}{c}.038 \\
(.046\end{array}$ \\
\hline & & & & $\begin{array}{l}.589 \\
(.245)\end{array}$ & $\begin{array}{c}.564 \\
(.223)\end{array}$ & $\begin{array}{c}.788 \\
(.269)\end{array}$ & \\
\hline & & & & $\begin{array}{c}.280 \\
(.265)\end{array}$ & $\begin{array}{l}-.085 \\
(.214)\end{array}$ & $\begin{array}{l}-.270 \\
(.248)\end{array}$ & \\
\hline $\begin{array}{l}-.124 \\
(.046)\end{array}$ & $\begin{array}{l}-.137 \\
(.05)\end{array}$ & $\begin{array}{l}-.139 \\
(.047)\end{array}$ & $\begin{array}{l}-.137 \\
(.047)\end{array}$ & $\begin{array}{l}-.148 \\
(.058)\end{array}$ & $\begin{array}{l}-.125 \\
(.058)\end{array}$ & $\begin{array}{l}-.104 \\
(.054)\end{array}$ & $\begin{array}{l}-.1 \\
(.0\end{array}$ \\
\hline
\end{tabular}

$2^{\text {nd }}$ highest bid

Sole bidder

Monthly oil price

.178
$(.114)$

$.242 \quad .140$

.131

$-.069$

County success rate

$\begin{array}{ll}.638 \quad .575 \\ (.166) & (.130)\end{array}$

(.153)

(.166) (.130)

$\begin{array}{lll}.573 & .539 \quad .537\end{array}$

Tract size

$$
\begin{array}{ll}
-.218 \quad-.210 \\
(.041) & (.039)
\end{array}
$$

Tract depth?

No Yes Yes

$(.039) \quad(.039)$

Contract characteristics?

No

$$
\text { No }
$$

No

Yes

No

Yes

Yes

Yes

Firm F.E.*

Monthly oil price?

No No

\section{No No}

No

Yes

Yes

Yes

Year F.E.?

Firm F.E.?

Sample size

Adjusted $\mathrm{R}^{2}$

Yes Yes

Yes

No

No Yes No

Yes Yes

Yes

Yes

Yes

Yes

Yes

Yes

$14032 \quad 13668 \quad 13104-12765-14032-12765-12765-12$

.715

.717

.723

.729

14032

$\begin{array}{lll}12765 & 12765 & 12765\end{array}$

${ }^{a}$ Notes (continued):

3. Cash flow is deflated by net property, plant and equipment at the beginning of the fiscal year. Bid price per acre and monthly oil price are expressed in $\$ 2000$. Tract size is measured in acres. Cash flow, bid price per acre, tract size, monthly oil price and $2^{\text {nd }}$ highest bid are all expressed in logarithms. We use a linear spline of the cash flow variable in columns 5 to 7 (Panel A) and 5 to 8 (Panel B). "Cash flow-spline 1", "cash flow-spline 2," and "cash flow-spline 3" respectively correspond to the 1ow cash flow levels (below the 33rd percentile of the cash flow distribution), the medium cash flow levels (between 33rd and 66th percentile of the cash flow distribution) and the high cash flow levels (above 66th percentile of the cash flow distribution).

4. Standard errors are corrected for clustering of the error term at the firm level. 
Table VII: Tract Level Characteristics ${ }^{a}$

\begin{tabular}{|c|c|c|c|c|c|c|c|c|c|c|}
\hline \multirow[t]{2}{*}{ Dep. Var.: } & \multirow{2}{*}{$\begin{array}{l}\text { Tract } \\
(1)\end{array}$} & \multirow{2}{*}{$\begin{array}{r}\text { Size } \\
\quad(2)\end{array}$} & \multicolumn{2}{|c|}{$\begin{array}{l}\text { Presence } \\
\text { in County }\end{array}$} & \multicolumn{2}{|c|}{$\begin{array}{l}\text { County } \\
\text { Success }\end{array}$} & \multicolumn{2}{|c|}{$\begin{array}{l}\text { Number } \\
\text { of Bids }\end{array}$} & \multicolumn{2}{|c|}{$\begin{array}{c}\text { Next } \\
\text { Bid }\end{array}$} \\
\hline & & & $(3)$ & $(4)$ & $(5)$ & $(6)$ & $(7)$ & $(8)$ & $(9)$ & $(10)$ \\
\hline Cash flow & $\begin{array}{l}.010 \\
(.015)\end{array}$ & $\begin{array}{l}.018 \\
(.015)\end{array}$ & $\begin{array}{l}.145 \\
(.940)\end{array}$ & $\begin{array}{c}.344 \\
(.549)\end{array}$ & $\begin{array}{l}-.010 \\
(.013)\end{array}$ & $\begin{array}{l}-.011 \\
(.012)\end{array}$ & $\begin{array}{l}.163 \\
(.070)\end{array}$ & $\begin{array}{l}.149 \\
(.061)\end{array}$ & $\begin{array}{l}-.005 \\
(.082)\end{array}$ & $\begin{array}{c}.001 \\
(.089)\end{array}$ \\
\hline Tobin's Q & $\begin{array}{l}.005 \\
(.006)\end{array}$ & $\begin{array}{l}-.001 \\
(.007)\end{array}$ & $\begin{array}{c}3.683 \\
(1.381)\end{array}$ & $\begin{array}{l}2.038 \\
(.528)\end{array}$ & $\begin{array}{l}-.022 \\
(.010)\end{array}$ & $\begin{array}{l}-.013 \\
(.010)\end{array}$ & $\begin{array}{l}-.102 \\
(.081)\end{array}$ & $\begin{array}{l}-.070 \\
(.060)\end{array}$ & $\begin{array}{l}-.160 \\
(.111)\end{array}$ & $\begin{array}{l}-.113 \\
(.130)\end{array}$ \\
\hline Monthly oil price & $\begin{array}{l}-.034 \\
(.028)\end{array}$ & & $\begin{array}{c}1.683 \\
(1.548)\end{array}$ & & $\begin{array}{l}-.029 \\
(.036)\end{array}$ & & $\begin{array}{l}1.123 \\
(.174)\end{array}$ & & $\begin{array}{l}1.072 \\
(.260)\end{array}$ & \\
\hline $\begin{array}{l}\text { Firm F.E.* } \\
\text { Monthly oil price? } \\
\text { Year F.E.? } \\
\text { Firm F.E.? } \\
\text { Sample size } \\
\text { Adjusted } \mathrm{R}^{2}\end{array}$ & $\begin{array}{c}\text { No } \\
\text { Yes } \\
\text { Yes } \\
20984 \\
.060\end{array}$ & $\begin{array}{c}\text { Yes } \\
\text { Yes } \\
\text { Yes } \\
20984 \\
.066\end{array}$ & $\begin{array}{c}\text { No } \\
\text { Yes } \\
\text { Yes } \\
20408 \\
.519\end{array}$ & $\begin{array}{c}\text { Yes } \\
\text { Yes } \\
\text { Yes } \\
20408 \\
.576\end{array}$ & $\begin{array}{c}\text { No } \\
\text { Yes } \\
\text { Yes } \\
20199 \\
.285\end{array}$ & $\begin{array}{c}\text { Yes } \\
\text { Yes } \\
\text { Yes } \\
20199 \\
.298\end{array}$ & $\begin{array}{c}\text { No } \\
\text { Yes } \\
\text { Yes } \\
20984 \\
.317\end{array}$ & $\begin{array}{c}\text { Yes } \\
\text { Yes } \\
\text { Yes } \\
20984 \\
.321\end{array}$ & $\begin{array}{c}\text { No } \\
\text { Yes } \\
\text { Yes } \\
3736 \\
.707\end{array}$ & $\begin{array}{c}\text { Yes } \\
\text { Yes } \\
\text { Yes } \\
3736 \\
.715\end{array}$ \\
\hline
\end{tabular}

${ }^{a}$ Notes:

1. The sample is all bids by COMPUSTAT firms between 1963 and 1999 in columns 1 to 8 and all winning bids in auctions where there was a second bidder in columns 9 and 10. Data sources: Mineral Management Services and COMPUSTAT (see Section 3 for details).

2. "Presence in county" represents the number of tracts previously won by that firm in that county in prior auctions (we also control in columns 3 and 4 for the total number of tracts auctioned off in that county in prior auctions). "County success" is defined as the fraction of productive tracts among all the tracts that were auctioned off in that county prior to that tract. "Number of bids" is the number of independent bids the tract received. "Next bid" refers to the second highest bid on the tract. "Monthly oil price" refers to the price of a barrel of oil in the month the tract was auctioned off.

3. Cash flow is deflated by net property, plant and equipment at the beginning of the fiscal year. Tract size is measured in acres. Cash flow, tract size, next bid and monthly oil price are all expressed in logarithms.

4. Standard errors are corrected for clustering of the error term at the firm level. 
Table VIII: Tract Level Productivity ${ }^{a}$

\section{Dependent Variable: Productive Tract? $(\mathrm{Y}=1)$}

$\begin{array}{ccccccccc}\text { OLS } & \text { IV } & \begin{array}{c}\text { Reduced } \\ \text { Form }\end{array} & \text { OLS } & \text { IV } & \text { OLS } & \text { IV } & \text { OLS } & \text { IV } \\ (1) & (2) & (3) & (4) & (5) & (6) & (7) & (8) & (9) \\ & & & & & & & & \\ .088 & -.137 & & .089 & -.145 & .089 & -.126 & .088 & -.161 \\ (.004) & (.082) & & (.004) & (.090) & (.004) & (.087) & (.004) & (.115)\end{array}$

$\begin{array}{lcc}\text { Bid price } & .088 & -.137 \\ \text { per acre } & (.004) & (.082)\end{array}$

Cash flow-

Cash flow-

spline 2

Cash flow-

spline 3

Monthly oil price

\begin{tabular}{cccccc}
.080 & .177 & .062 & .142 & .032 & .085 \\
$(.033)$ & $(.049)$ & $(.035)$ & $(.045)$ & $(.039)$ & $(.042)$ \\
& & & & & \\
& & & & -.025 & -.041 \\
& & & & $(.012)$ & $(.014)$ \\
& & & & & \\
No & No & Yes & Yes & Yes & Yes \\
No & No & No & No & Yes & Yes \\
Yes & Yes & Yes & Yes & Yes & Yes \\
Yes & Yes & Yes & Yes & Yes & Yes \\
20972 & 20972 & 20972 & 20972 & 19946 & 19946 \\
\hline
\end{tabular}

Tobin's Q

Tract char's?

No No

Contract char's?

No

Year F.E.?

Yes

Firm F.E.?

Yes Yes

No

Yes

Yes

20972

19946

${ }^{a}$ Notes:

1. The table presents regressions of tract-level productivity on bid price and cash flow. The sample is all bids by COMPUSTAT firms between 1963 and 1999. The dependent variable in all columns is a dummy variable that equals 1 if the tract was designated as productive before the end of the exploration period. Data sources: Mineral Management Services and COMPUSTAT (see Section 3 for details).

2. Tract characteristics include tract size, minimum and maximum depth. Contract characteristics include dummy variables for royalty rate, rental rate and length of lease. Monthly oil price refers to the price of a barrel of oil in the month the tract was auctioned off. Cash flow is deflated by net property, plant and equipment at the beginning of the fiscal year. Tract size is measured in acres. Cash flow, bid price per acre, tract size, monthly oil price are all expressed in logarithms.

3. We use a linear spline of the cash flow variable as control in the reduced form regression (column 3 ) and as instrument for bid price per acre in the IV regressions (columns 2, 5, 7 and 9). "Cash flow-spline 1", "cash flow-spline 2," and "cash flow-spline 3" respectively correspond to the 1ow cash flow levels (below the 33rd percentile of the cash flow distribution), the medium cash flow levels (between 33rd and 66th percentile of the cash flow distribution) and the high cash flow levels (above 66th percentile of the cash flow distribution).

4. Standard errors are corrected for clustering of the error term at the firm level except in the IV regressions. 
Table IX: Firm Level Productivity ${ }^{a}$

Dep. Var.: Number of Productive Leases

\begin{tabular}{lcccc} 
& Unweighted & \multicolumn{2}{c}{$\begin{array}{c}\text { Ownership } \\
\text { Weighted }\end{array}$} \\
& & & & \\
& $(1)$ & $(2)$ & $(3)$ & $(4)$ \\
Cash flow & & & & \\
& -.243 & & -.219 & \\
& $(.681)$ & & $(.331)$ & \\
Cash flow-spline 1 & & .342 & & -.128 \\
& & $(.867)$ & & $(.451)$ \\
& & & & \\
Cash flow-spline 2 & & -5.96 & & -1.99 \\
& & $(4.99)$ & & $(2.80)$ \\
Cash flow-spline 3 & & .776 & & .415 \\
& & $(1.50)$ & & $(.952)$ \\
Year F.E.? & & & & \\
Firm F.E.? & Yes & Yes & Yes & Yes \\
Sample size & 1033 & 1033 & Yes & Yes \\
Adj. R ${ }^{2}$ & .510 & .520 & 463 & 1033 \\
\hline \hline
\end{tabular}

${ }^{a}$ Notes:

1. The table presents regressions of total number of productive leases on cash flow at the firm level. The dependent variable is the number of tracts bid on in a given year that ended up being productive. Cash flow is measured in the year the bids for these tracts were placed. Columns 1 and 2 present simple counts; columns 3 and 4 present ownership-weighted counts, where ownership is the fraction of ownership the firm has in each bid. The firms included in the sample are those COMPUSTAT firms that have placed at least one bid in the MMS data between 1963 and 1999. Observations for these firms are included only for bidding years. Data sources: Mineral Management Services and COMPUSTAT (see Section 3 for details).

2. Cash flow is deflated by net property, plant and equipment at the beginning of the fiscal year. Cash flow is expressed in logarithm.

3. We use a linear spline of the cash flow variable in columns 2 and 4. "Cash flow-spline 1", "cash flow-spline 2," and "cash flow-spline 3" respectively correspond to the 1ow cash flow levels (below the 33rd percentile of the cash flow distribution), the medium cash flow levels (between 33rd and 66th percentile of the cash flow distribution) and the high cash flow levels (above 66th percentile of the cash flow distribution).

4. Standard errors are corrected for clustering of the error term at the firm-level. 
Table X: Total Resources Found in Tract ${ }^{a}$

Dep. Var. :

Bid price

Per acre

Cash flow

Monthly oil price

Months producing dummies?

Firm F.E.*

Monthly oil price?

Year F.E.?

Firm F.E.?

Sample Size

Adjusted $\mathrm{R}^{2}$

\section{Gas Production}

$(1)$
-.005
$(.044)$

$(2)$

$(3)$
-.024
$(.044)$

(4)

$-.024$

(.044)

\section{.026}

(.16)

$-.071$

(.175)

$$
\begin{array}{ll}
-.068 & -.162 \\
(.56) & (.832)
\end{array}
$$

Yes
No

Yes

Yes

$$
\text { No }
$$

Yes

Yes

Yes

1845

.367

\begin{tabular}{ccc} 
Yes & Yes & Yes \\
Yes & Yes & Yes \\
1260 & 1845 & 1260 \\
.374 & .365 & .372 \\
\hline
\end{tabular}

\section{Oil Production}

$(5)$
-.146
$(.228)$

(6)

(7)

(.237)

$$
\text { (1.967) }
$$

$\begin{array}{ll}-2.648 & -8.220\end{array}$

$(3.496) \quad(4.87)$

-5.098
$(1.967)$
-8.220
$(4.87)$

\begin{tabular}{lccc} 
Yes & Yes & Yes & Yes \\
No & No & Yes & Yes \\
& & & \\
Yes & Yes & Yes & Yes \\
Yes & Yes & Yes & Yes \\
493 & 316 & 493 & 316 \\
.428 & .473 & .528 & .671 \\
\hline
\end{tabular}

${ }^{a}$ Notes:

1. The table presents regressions of tract-level gas and oil production on bid price and cash flow. The sample is productive tracts bid on by COMPUSTAT firms since 1978. Data sources: Mineral Management Services and COMPUSTAT (see Section 3 for details).

2. Monthly oil price refers to the price of a barrel of oil in the month the tract was auctioned off. Months producing dummies are dummy variables for the number of months of reported production.

3. Cash flow is deflated by net property, plant and equipment at the beginning of the fiscal year. Cash flow, bid price per acre, monthly oil price and production of gas and oil are all expressed in logarithms.

4. Standard errors are corrected for clustering of the error term at the firm level. 


\section{Table XI: Bidding Before and After $1985^{a}$}

Dep. Var.: Bid Price Per Acre

Sample: $\quad$ All Bids $\quad$ Winning Bids

Pre-85 Post-85 Pre-85 Post-85

(1) (2) (3) $\quad(4)$

\begin{tabular}{lcccc} 
Cash flow-spline 1 & -.128 & .037 & -.133 & .061 \\
& $(.103)$ & $(.06)$ & $(.174)$ & $(.065)$ \\
& & & & \\
Cash flow-spline 2 & .618 & .591 & .884 & .765 \\
& $(.307)$ & $(.339)$ & $(.41)$ & $(.356)$ \\
& & & & \\
Cash flow-spline 3 & -.163 & -.277 & -.038 & -.213 \\
& $(.208)$ & $(.244)$ & $(.282)$ & $(.266)$ \\
& & & & \\
Year F.E.? & Yes & Yes & Yes & Yes \\
Firm F.E.? & Yes & Yes & Yes & Yes \\
Sample size & 8848 & 10336 & 5106 & 7659 \\
Adj. R & .398 & .177 & .453 & .197 \\
\hline \hline
\end{tabular}

\footnotetext{
${ }^{a}$ Notes:

1. This table replicates the regressions in column 5 of Panels A and B of Table 6 but breaks down the sample into pre and post 1985. See notes to that table for details.
} 
Table XII: Productivity Before and After $1985^{a}$

Dep. Var.: Productive Tract? $(\mathrm{Y}=1)$

\begin{tabular}{lcccc} 
& \multicolumn{2}{c}{ Pre-85 } & \multicolumn{2}{c}{ Post-85 } \\
& OLS & IV & OLS & IV \\
& & & & \\
& $(1)$ & $(2)$ & $(3)$ & $(4)$ \\
& & & & \\
Bid price & .104 & -.149 & .061 & .109 \\
per acre & $.004)$ & $(.221)$ & $(.006)$ & $(.123)$ \\
& & & & \\
Monthly oil price & .256 & .448 & -.106 & -.103 \\
& $(.069)$ & $(.182)$ & $(.037)$ & $(.041)$ \\
& & & & \\
Contract characteristics? & Yes & Yes & Yes & Yes \\
Tract characteristics? & Yes & Yes & Yes & Yes \\
Year F.E.? & Yes & Yes & Yes & Yes \\
Firm F.E.? & Yes & Yes & Yes & Yes \\
Sample size & 9528 & 9528 & 10418 & 10418 \\
Adj. R & & & 0.129 & \\
& 0.190 & & & \\
\hline \hline
\end{tabular}

${ }^{a}$ Notes:

1. This table replicates the regressions in columns 8 and 9 of Table 8 but breaks down the sample into pre and post 1985 . See notes to that table for details. 